\section{Around About}

\section{Science Spending Down}

Sciences programmes fared fairly well in the US 1996 budget which has finally been agreed by Congress and the President. Nonmilitary science and technology spending will be $3 \%$ less than for fiscal 1995 ( $5 \%$ with inflation) as compared with a $9 \%$ cut for the total non-military budget.

The UK's Science and Technology Office reports in its annual Forward Look that government spending on research and technology decreased by $26 \%$ in real terms in the period 1985-95. Most of the decline has come from reductions in spending for defence and by government departments, in line with the government's commitment to make industry responsible for investment in these areas. Univer-

\section{Dutch Physics Festival}

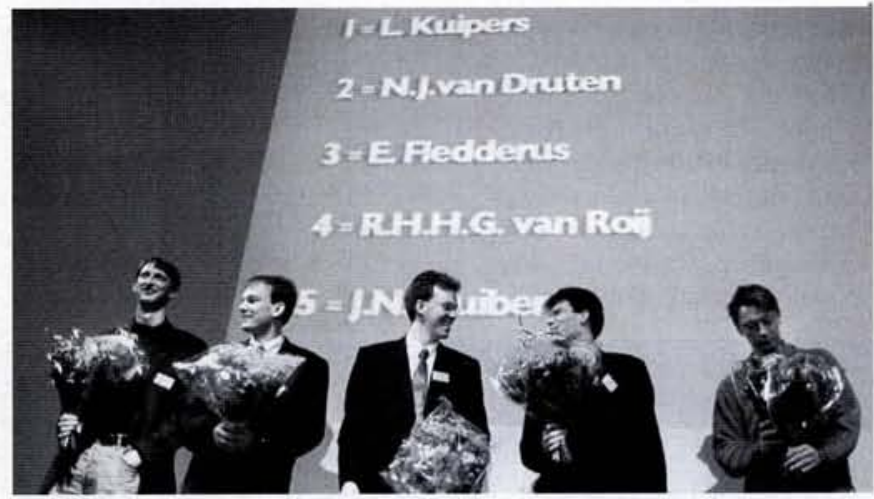

The Jaarbeurs Congress Centre in Utrecht saw over a thousand physicists and other physics' enthusiasts come together on 11 April to celebrate the 75th anniversary of The Netherlands Physical Society and the 5oth anniversary of the Dutch physics research council FOM. The crowd was treated on an exhibition on the current state of physics in Holland, a session on physics and science policy, a special talk by good old Nico van Kampen, a concert by an orchestra of about 50 physicists, drinks, etc.

A highlight of the day was the final of a young physicists' lecture competition, which started off in January with 31 candidates. The competition's five best speakers were invited sity and research council spending increased in the same period by $13 \%$, so its share of total government S\&T spending rose from $35 \%$ in 1985 to $55 \%$ in 1995 .

Germany's research minister has reported that federal funding for research as a percentage of GDP decreased in Germany from a plateau of $2.9 \%$ in $1987-91$ to $2.3 \%$ in 1995 . There has also been a considerable reduction in the proportion of domestic research financed by industry.

\section{UK Physics Labs Stay Public}

The UK government has announced following reviews of 12 out of 40 national labs employing 20000 that the Central Laboratory for the Research Councils (CLRC) formed in 1995 by merging the Daresbury and RutherfordAppleton laboratories will remain in the public sector. The CLRC, with 1900 staff and the UK's main the switchable yttrium the first author, was the cover story for the 21 March 1996 issue of Nature. [H. Eggen, Utrecht] provider of physics facilities, was deemed to be already running successfully along private-sector lines with most work coming from competitive tenders. The CLRC inaugurated Titania, the world's most powerful UV laser (10 TW/30o fs pulses), on 2 April. The facility will be used for plasma physics studies, aspects of inertial confinement fusion, $\mathrm{x}$-ray laser development, and the generation and application of extreme UV laser harmonics.

\section{ESTA Backs Science and ICF}

The European Union's European Science and Technology Assembly (ESTA) argues in a recent statement that every programme in the EU's next Framework should include a basic research component to fund "bottom-up" proposals (few have one at present and they are heavily oversubscribed). ESTA also says that the European Commission should develop "common scientific objectives" between national research councils and European research organizations.

Meanwhile, ESTA's 20member bureau is seeking a successor to the ESTA chairman Jan Borgman, whose resignation protesting ESTA's inadequate resources for its administrative workload involving several working groups is pending.

An ESTA draft report, and the first on a subject of its own choosing, has recommended that the percentage of EU fusion programme spending on inertial confinement fusion (ICF) should be increased from $1-2 \%$ to $10 \%$ by diverting funds from magnetic confinement fusion in order to develop an ICF programme comparable to those in the US and Japan. Meanwhile, the Joint European Torus has won final approval for a three-year extension until the end of 1999 to provide research in support of the thermonuclear fusion reactor ITER.

W 7-X Fusion Reactor Agreed

Agreements have been signed by the European Union's fusion programme, the German federal government and the state of Mecklenburg-Vorpommern for the construction of the $320 \mathrm{MDM}$ Wendelstein 7 -X stellarator fusion reactor at the Institute of Plasma Physics (IPP) Greifswald laboratory. Tenders for constructing the facility, with a planned staff of 300 , will now be sent out and completion by 2004 is planned.

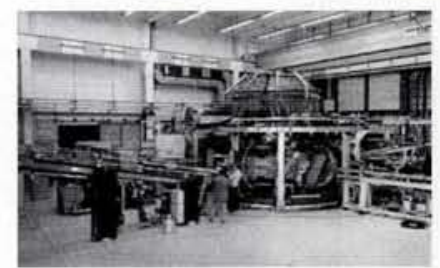

The IPP, Garching, Wendelstein 7-AS fusion stellarator. Construction of the next in the series, an optimised 7-X version, starts shortly at the IPP's Greifswald laboratory, the former East German Institute of Low-Temperature Plasma Physics.

Experiments in support of ITER mean that $45 \%$ of the investment comes from the EU, and the IPP hopes that there will be commitments in future Framework programmes to cover operating costs.

COBRAS/SAMBA Selected

The European Space Agency's (ESA) Space Science Advisory Committee has recommended COBRAS/SAMBA as the agency's third, approximately $350 \mathrm{MECU}$, Horizon programme mediumsized $\mathrm{M}_{3}$ mission. The proposed launch data of around 2004 is one year later than originally foreseen owing to the $3 \%$ p.a. reduction in ESA's science budget that was agreed to by ESA Member States last year. COBRAS/SAMBA will offer 10-times greater sensitivity and 50-times more angular resolution than the COBE spacecraft that discovered irregularities in the cosmic radiation background in 1992. The other most highly ranked mission was Intermarsnet to study Mars, but there were doubts that NASA's launch date of 2003 could be met and an Ariane 5 launch was too expensive. The committee recommended that the ESA Executive consider the lunar orbiter MORO in the framework of ESA's lunar initiative, which was recommended by the last meeting of ESA ministers. Modest support should be given to a simplified version of STEP (low-cost missions to test the equivalence principle have been proposed by the French CNES space agency and by NASA). Finally, a less ambitious stellar seismology mission of the type being considered by some Member States should come before the proposed STARS mission to probe the internal structures of a wide range of stars. mirror, which with Huiberts as

\section{Neutrons for the US}

Following the US Department of Energy (DoE) decision last year to cancel the $3000 \mathrm{M} \$ \mathrm{US}$ 
Advanced Neutron Source, the DoE Basic Energy Sciences Advisory Committee has made preliminary recommendations to a report that will be finalised in a few months. It argues that a $5 \mathrm{MW}$ Pulsed Spallation Neutron Source (PSNS) at the Oak Ridge national lab (the DoE designated preferred ălternative site), which would be competitive with the proposed European Spallation Source, cannot be built within the 1000 MSUS ceiling set previously by DoE. So the committee recommends a MW source upgradable to $5 \mathrm{MW}$.

A proposed upgrade to $1 \mathrm{MW}$ of Argonne's Intense Pulsed Neutron Source was not recommended because it would cost much more than 100 M\$US. Meanwhile, defence and energy research programmes should collaborate on plans for a proposed 1 MW long-pulse source at the Los Alamos national lab.

The committee also recommends upgrades of the 30-year old High Flux Beam Reactor and the High Flux Isotope Reactor at the Brookhaven and Oak Ridge national labs, respectively, to provide neutron capacity while the PSNS is being built. The Los Alamos, Brookhaven and Argonne labs as well as the LawrenceBerkeley lab are presently collaborating on the PSNS design.
Switzerland above Average An evaluation of physics research in Switzerland by the Swiss Research Council has concluded that the country's physicists and astrophysicists have successfully weathered the structura transition from traditional areas to a more engineering-oriented approach without loosing the competitive edge. The amount of physics and astrophysics (P\&A) research carried out equals that undertaken by most industrial countries. For instance, 1993 spending on $\mathrm{P} \& \mathrm{~A}$ as a percentage of the GDP was about the same as for Denmark in 1990 and some $20 \%$ higher than for Sweden in 1991. However, the quality of the output can be said to be above average (a relative citation index of 2.00 in 1992 is the highest among developed countries). Specific areas (computational physics, optics, microtechnology, parts of semiconductor physics) need strengthening, taking into account contributions to international organizations. Meanwhile, the government has requested preparatory work so that the Paul Scherrer Institute can submit its Swiss Light Source synchrotron proposal to parliament for a final decision in 1997. Letters of Intent from potential users are sought [http://www1.psi.ch].

\section{Munich Reactor Approved}

The new FRM-II research reactor in Garching near Munich received its first partial license on 9 April, thus approving the design and allowing construction of the buildings. The budget of $720 \mathrm{MDM}$ for the facility has also been settled so construction has started. A second partial license is needed for the installation of the nuclear components, and a third for the operation of the reactor.

The first license is an important milestone and marks the end of nearly 15 year's of planning and discussions. The way is now open to realize the most powerful and modern neutron source in Germany, which, when finished in about 5-6 years, will supply scientists with experimental conditions for neutron experiments superior to those available in Berlin, Garching, Geesthacht and Julich.

FRM-II, with capacity for about 40 experimental installations and instruments, will be operated by the TU Munich as a national institution. Ten instruments are budgeted for; others can be installed by interested research groups.

The $20 \mathrm{MW}$ reactor is cooled by light water and moderated by heavy water. A relatively high ratio of neutron-to-reactor power comes from the compact size of the core and the use of highly enriched U-235. The reactor will be equipped with a vertical cold neutron source, a hot source and ten horizontal, one vertical and two inclined beam tubes. The neutron flux expected at the cold sources and at the tube inputs is 4- $6 \times 10^{14} \mathrm{n} / \mathrm{cm}^{2} \mathrm{~s}^{1}$. A large beam tube will take up to six neutron guides into an experimental area with additional laboratories. Neutron switches will allow each primary guide to be split up into three partial beams, thus creating a large number of "guide-end positions". Two neutron beams can be extracted from each of the standard beam tubes to provide two instruments per beam hole. One of the horizontal beam tubes is designed for extracting charged fusion products which can be

\section{People}

The Fritz London Memorial Award for outstanding contributions to low temperature physics, awarded every three years at the International Conference on Low Temperature Physics, has been won by M.H.W. Chan (Pennsylvania State University, PA, USA.) for innovative and precise experimental studies of phase transitions in fluids; and by E.A. Cornel and C. Wieman (National Institutes of Standards and Technology and University of Colorado, USA.) for demonstrating Bose-Einstein condensation of weakly interacting atoms.

The first Surface Structure Prize awarded by the International Conference on the Structure of Surfaces (ICSOS) has been won by J.B. Pendry for far-reaching, diverse, fundamental and practical contributions to quantitative surface structure determination.

J. Solana, the new Secretary General of NATO, trained as a physicist, having been awarded a PhD by the Universidad Autónoma de Madrid. He then became professor of solid-state physics at the Universidad Complutense de Madrid, before serving as Spain's Minister for Education and Science (1988-92) and as

\section{J. Solana}

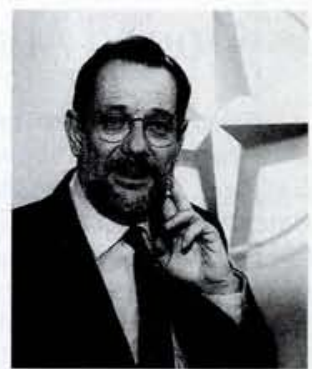

the Minister of Foreign Affairs. F. Menzinger, scientific attaché at Italy's Permanent Mission in Geneva and professor of physics at the University of Rome "Tor Vergata" succeeded R.W. Newport as the Chairman of the European Synchrotron Radiation Facility's Council on 1 January, and C. Kunz, professor of experimental physics at the University of Hamburg succeeded B. Lengeler as the Director of Research.

B. Frois $\left(\mathrm{IN}_{2} \mathrm{P}_{3}\right.$, Saclay) has been appointed chairman of IUPAP's new International Commission for Nuclear Physics. S. Gàles, the new NuPECC President, is a member.

F. Saris, formerly Director of AMOLF, Amsterdam, has become the ECN Petten's Director of Research, and G. Van Niggelkoop, Professor at the Free University, Amsterdam, has become the Director of NIKHEF, Amsterdam.

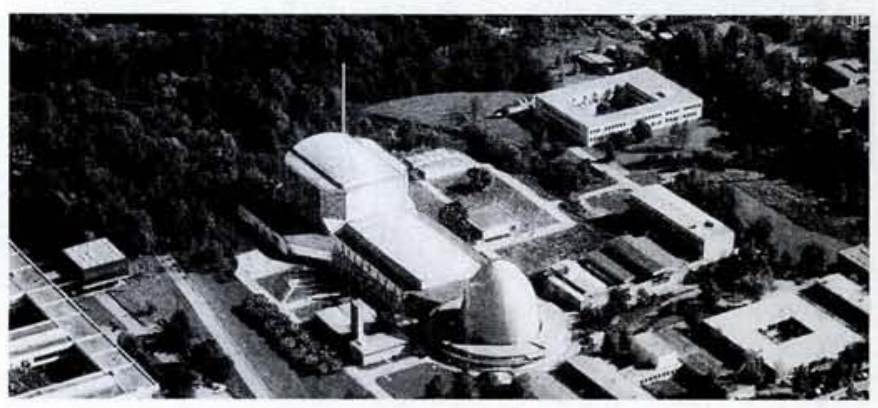

A photomontage showing a model of the new Forschungsreaktor München-II (FRM-II) behind the "egg" of the TU Munich's existing research reactor.

accelerated for heavy-ion reactions. A U-235 target at the input of another horizontal tube produces fast-fusion neutrons for cancer therapy and computer tomography with fast neutrons. Also planned is an installation for producing radioactive samples, especially phosphorus for doping semiconductor silicon.

At a time when research with neutrons becomes more important and more in demand, and with older reactors becoming more difficult to refurbish, it is natural to make the best of new possibilities. It is for this reason that we have advocated operating the reactor with highly enriched U-235. In the same spirit, we want to do our best for the equipment and the instruments. We hope that we can bring worldwide experience and knowledge to the instrumentation by having scientific visitors during the next few years. We also hope that some of the neutron beams at FRM-II will become attractive enough for scientists from elsewhere so that we can create the fruitful international atmosphere which is fundamental for research. 